\title{
Exploring Factors That Influence the Uptake of Maternal Health Care Services by Women in Zimbabwe
}

\author{
Andrew Mupwanyiwa, Moses Chundu, Ithiel Mavesere, Modester Dengedza \\ Faculty of Business Management Sciences and Economics, University of Zimbabwe, Harare, Zimbabwe \\ Email: mtgjcc@gmail.com
}

How to cite this paper: Mupwanyiwa, A., Chundu, M., Mavesere, I., \& Dengedza, M. (2020). Exploring Factors That Influence the Uptake of Maternal Health Care Services by Women in Zimbabwe. Open Journal of Social Sciences, 8, 46-70. https://doi.org/10.4236/jss.2020.810005

Received: September 7, 2020

Accepted: October 12, 2020

Published: October 15, 2020

Copyright $\odot 2020$ by author(s) and Scientific Research Publishing Inc. This work is licensed under the Creative Commons Attribution International License (CC BY 4.0).

http://creativecommons.org/licenses/by/4.0/

\section{(c) (i) Open Access}

\begin{abstract}
The study investigated factors that influence the uptake of maternal healthcare services by women in Zimbabwe, using a logit model. Data from the Zimbabwe Demographic Health Survey (ZDHS, 2015) was used. Deteriorating maternal health indicators motivated the study. The effect of socio-economic and demographic factors on the probability of utilising maternal healthcare services was examined. Descriptive statistics and a logit model were used for data analysis. Results from the logit model show that region of residence, insurance cover, educational level, employment status, maternal age, birth order, place of residence, number of living children, maternal age and household income all influence the utilisation of maternal healthcare services by women in Zimbabwe. Basing on research findings, the study recommends that relevant authorities make more available vocational training centres and education institutions since education was found to influence the uptake of maternal healthcare services. There is need to encourage family planning so as to reduce the number of children, especially among the apostolic sect, which affects the uptake of maternal healthcare. Compulsory national health insurance schemes could be adopted to mitigate the effect of low income that discourages the use of institutional facilities for delivery. The issue of balanced regional development needs to be pursued through accelerating devolution to ensure equal access to maternal healthcare facilities in all provinces.
\end{abstract}

\section{Keywords}

Maternal Healthcare, Health Insurance, Infant Mortality, Health Infrastructure, SDG3 


\section{Introduction and Background}

\subsection{Introduction}

Globally, a woman dies every minute from difficulties related to childbirth (World Health Organisation, 2013). Maternal related difficulties are a key basis for most ill-health and mortality among women within child bearing age worldwide (World Health Organisation, 2016). The World Health Organisation (WHO), in 2015, recorded approximately 303,000 maternal deaths world-wide. Out of this, Sub-Saharan Africa alone accounted for 201,000 (66\%). World Health Organisation (2013) itemised the maternal mortality ratio in developing countries as 230 women per 100 thousand births, versus 16 women per 100 thousand in developed countries. The problems of maternal, infant and child mortality, therefore, remain major health concerns in the developing world and Zimbabwe in particular.

Maternal health refers to the health of women during pregnancy, childbirth and the postpartum period (World Health Organisation, 2013). Maternal healthcare service utilisation is important for the improvement of maternal outcomes. It consists of a large range of curative and preventative health services that are very important to the health status of women in the child bearing ages of 15 - 49 years. Maternal healthcare consists of three main components; antenatal care utilisation (ANC), which includes the uptake of Tetanus Toxoid injection, delivering in a health institution and postnatal care (PNC) service utilisation. The importance of the use of antenatal care, delivering in a health institution and postnatal care utilisation has been emphasised in literature as services that can be a panacea to pregnant related complications and maternal mortality

(Fauveau, Koenig, Chakraborty, \& Chowdhury, 1988). Furthermore, the use of Tetanus Toxoid injection reduces maternal morbidity as well as mortality.

The use of PNC is paramount to deal with maternal mortality since most of the deaths occur within few days after delivery. Antenatal healthcare includes medical interventions such as injections against tetanus and advice that a woman receives during pregnancy. This is a key entry point for pregnant women to receive a broad range of health promotion and preventive health services including knowledge about healthy practices during pregnancy, nutritional support, prevention and treatment of anaemia, diagnosis and treatment of other diseases. Routine ANC can be provided both at household level and primary healthcare centres helping to assure a link to higher levels of care when needed. WHO recommends that a woman without complications should have at least four ANC visits starting from the first trimester to get sufficient prenatal care to minimize pregnancy-related complications.

For policy-makers to design and implement targeted evidence-based policy interventions in the health arena, there is need to know what is most likely to improve maternal healthcare behaviours based on empirical evidence. Given shallow empirical literature on maternal healthcare service utilisation in Zimbabwe, it is important to develop further evidence providing more light on the 
interaction between utilisation of maternal healthcare services and its determinants. Therefore, this study investigates the factors influencing the uptake of maternal healthcare services in Zimbabwe.

\subsection{Background to the Study}

Zimbabwe's healthcare system is under the custodian of the Ministry of Health and Child Care (MOHCC). Zimbabwe adopted the Primary Health Care (PHC) approach in 1980 which resulted in one of the most celebrated healthcare systems in the region (Kadenge, Ndoro, \& Zwizwai, 1992; Kanyenze, Kando, Chitambara, \& Martens, 2012) that was characterised by low death rates, low prevalence of pandemics and quick response to outbreaks (MoHCC, 2016) ${ }^{1}$. The health services delivery platforms include primary, secondary, tertiary (provincial) and quaternary (central) facilities. The majority of these health facilities are at primary care level which refers complicated cases to the next levels of healthcare services. Mission and private sector facilities provide considerable services mostly in rural and urban areas, respectively. Most households, including pregnant women, first visit primary healthcare centres for attention before any referral, should it become necessary. As of 2016, there were 1118 primary healthcare facilities which constitute $78 \%$ of the total health facilities in the country (AHFoZ, 2016).

The high figures in maternal mortality and under-five mortality reflected in Table 1 are clear signs of poor maternal healthcare service utilisation in Zimbabwe, hence the need for urgent attention to maternal health issues in order to reduce avoidable causes of deaths in women and children. The pattern of maternal healthcare indicators reflected the broader macroeconomic developments. The 1990s saw government embrace the Economic Structural Adjustment Programme period (ESAP), which saw expenditure on health declining from $6.2 \%$

Table 1. Trends of maternal health indicators in Zimbabwe.

\begin{tabular}{|c|c|c|c|}
\hline \multirow{2}{*}{ Health indicator } & \multicolumn{3}{|c|}{ Year } \\
\hline & 1994 & 2009 & 2016 \\
\hline Maternal mortality rate & $\begin{array}{c}725 \text { deaths per } \\
100,000 \text { live births }\end{array}$ & $\begin{array}{c}960 \text { deaths per } \\
100,000 \text { live births }\end{array}$ & $\begin{array}{c}790 \text { deaths per } \\
100,000 \text { live births }\end{array}$ \\
\hline Under five mortality rate & $\begin{array}{c}77 \text { per } \\
1000 \text { live births }\end{array}$ & $\begin{array}{c}86 \text { per } \\
1000 \text { live births }\end{array}$ & $\begin{array}{c}57 \text { per } \\
1000 \text { live births }\end{array}$ \\
\hline Infant mortality rate & $\begin{array}{c}55 \text { per } \\
1000 \text { live births }\end{array}$ & $\begin{array}{c}60 \text { per } \\
1000 \text { live births }\end{array}$ & $\begin{array}{c}75 \text { per } \\
1000 \text { live births }\end{array}$ \\
\hline $\begin{array}{lc}\text { Life expectancy } & \text { Females } \\
& \text { Males }\end{array}$ & $\begin{array}{l}60 \text { years } \\
60 \text { years }\end{array}$ & $\begin{array}{l}44 \text { years } \\
43 \text { years }\end{array}$ & $\begin{array}{l}58 \text { years } \\
56 \text { years }\end{array}$ \\
\hline
\end{tabular}

Source: MoHCC (2017).

${ }^{1}$ The 1990s saw a complete reversal of the gains of the 1980s, with most indicators deteriorating dramatically as shown in Table 1, with maternal mortality in Zimbabwe standing at 790 (725 in the 1990s) deaths per 100 thousand live births as of 2016 (World Health Organisation, 2016). 
in 1990 to $4.2 \%$ in 1996 (Kawewe \& Dibie, 2000). This was made worse by a multiplicity of challenges which included; financial austerity, inflation and increased burden of disease attributed to the devastating effects of the human immune virus (HIV) and acquired immune deficiency syndrome (AIDS) pandemic. All this seriously affected the country's health delivery system and maternal health was not spared.

The period 2009-2013 under the Government of National Unity (GNU) was characterised by economic recovery and stability which improved people's incomes. Funding of the health sector by the Government of Zimbabwe generally improved since 2009. In 2012, funding towards the health sector was $8 \%$ of total government expenditure. However, this remained below the Abuja declaration commitment of 15\% of total government spending. Between 2009 and 2012, external funding toward the health sector notably increased from $\$ 167$ million in 2009 to $\$ 428$ million in 2012. As a result, most maternal health indicators improved during the period before they started to deteriorate again at the end of the GNU in 2013. Figure 1 further illustrates these deteriorating trends over this period.

Proper utilisation of maternal healthcare services by women in Zimbabwe is essential for good maternal health outcomes. Figure 2 and Figure 3 show the low levels of maternal care utilisation by women in Zimbabwe for two categories being ANC and delivery respectively explaining the unacceptable health outcomes discussed above. One of the key strategies towards reducing maternal death is increasing the number of pregnant women delivering at a health institution. Effective and proper medical attention by skilled personnel as well as good hygienic conditions are amongst the best ingredients towards reducing pregnancy complications and reducing mortality and morbidity to mothers and children. According to Zimbabwe Demographic Healthy Survey (ZDHS) 2015, the number of children delivered at health facilities has been on a declining trend as shown in Figure 3.

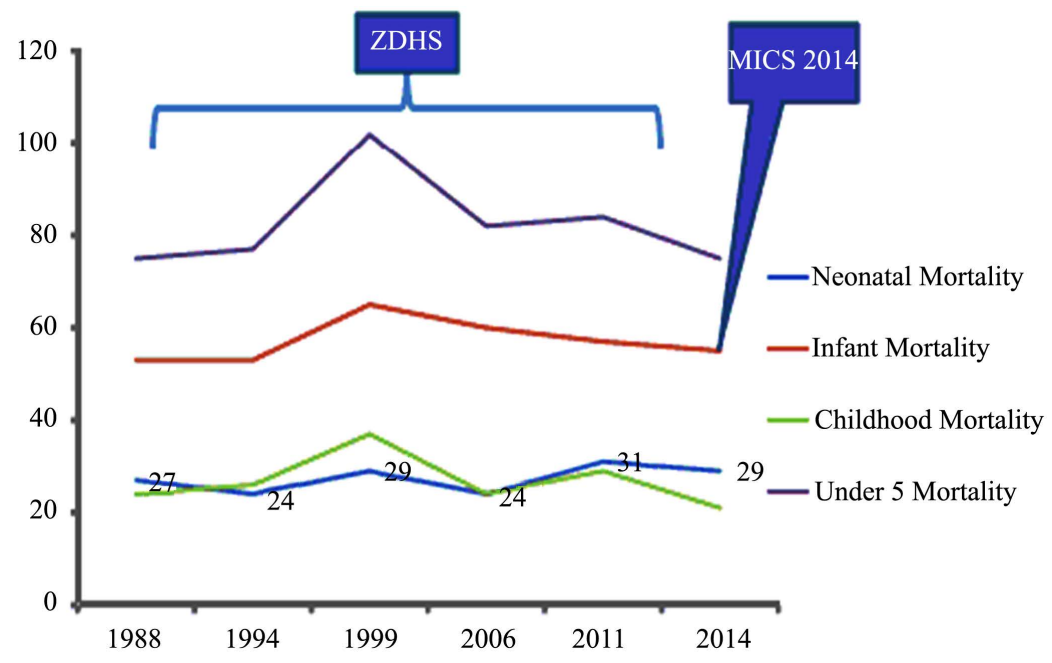

Figure 1. Maternal health outcome trends in Zimbabwe. 


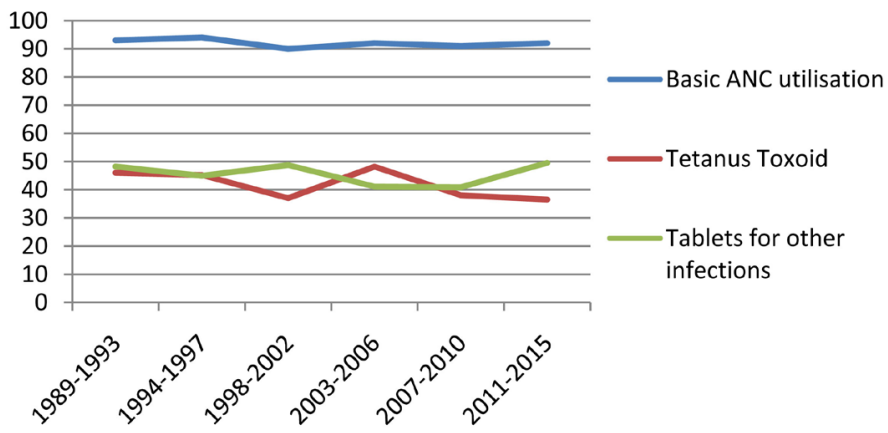

Figure 2. Percentage ANC utilisation by women in Zimbabwe.

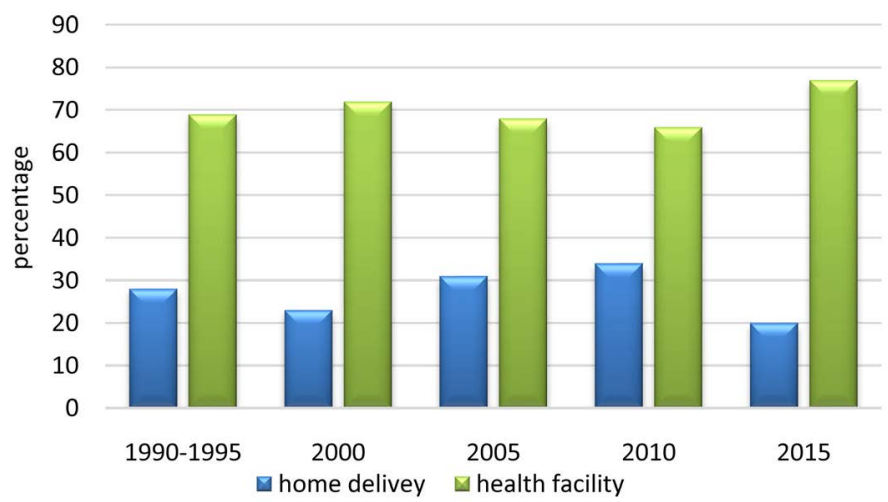

Figure 3. Trends in utilisation of places of delivery in Zimbabwe (Source: Extracted from DHS 1995/6, 1999/00, 2004/05 and2010/11 reports).

Even though institutional delivery increased as recorded in 2015 ZDHS and has been generally above home deliveries, the figures are not good enough to explain adequate maternal healthcare service utilisation that leads to improved health outcomes. A variety of reasons explains the decline in use of institutional delivery services during child delivery and increase in home delivery. Exorbitant and prohibitive user fees have impeded accessibility for institutional health services to many socio-economically marginalised households, leaving them with no option but to use home delivery services which are less expensive (World Health Organisation, 2013).

Safe motherhood programmes recommend that women receive a postnatal check within two days of delivery. In Zimbabwe, $68 \%$ of mothers received a postnatal check, but only $57 \%$ had a check in the first two days after delivery (ZimStat, 2015a). This shows that most of these women are at a high risk of dying from birth related problems, hence the need to know factors that influence the uptake of such postnatal care services within the prescribed period and design policies at addressing any causes of non-utilisation.

Generally, the number of women utilising maternal healthcare services has been on a downward since the turn of the millennium, against a considerable number of women dying as a result of maternal related problems. Low utilisation of institutional health facilities before delivery, (antenatal care), during child delivery, (institutional delivery) and after child delivery (postnatal care), is one 
of the major reasons that explain high maternal, infant and child mortality rates in Zimbabwe. Despite increased efforts in reducing maternal related deaths, such as increasing the number of healthcare centres that provide free maternal health services and removal of user fees in most public health institutions, maternal mortality continues to be unacceptably higher than WHO permissible levels of 71 deaths per 100 thousand live births. With such high levels of maternal mortality, the country could find it difficult to achieve Sustainable Development Goal (SDG) number $3^{2}$ after it also failed to achieve the Millennium Development Goal 5 target of 185 per 100 thousand live births.

It is against this background that the study sought to investigate the factors that influence the uptake of maternal healthcare services by women in Zimbabwe using household data from Zimbabwe Demographic Health Surveys 2015. The findings will provide some direction to the health policy key players in implementing future maternal healthcare programmes with an understanding of the factors that influence women choice of health facilities utilisation. Such an understanding is of paramount importance to direct and redirect interventions aimed at scaling up maternal healthcare service delivery nationally. This study will also add to the literature on the understanding of factors that determine the utilisation of the full maternal healthcare service package towards the achievement of SDGs.

\section{Literature Review}

\subsection{Theoretical Literature Review}

The general theoretical perspective of healthcare behaviour falls under a mixed demand-supply framework. This study only looked at factors affecting maternal healthcare service utilisation. The health-seeking behavioural models used to conceptualise demand for maternal healthcare services by pregnant women include the Andersen's Health Care Utilisation model (1968), Demand for Health Model by Grossman (1972), Choice Making Model by Young (1981), and Health Belief Model by Rosenstock, Stretcher, \& Becker, (1994) which are outlined below.

\subsubsection{Grossman's Demand for Health Model (1972)}

Grossman (1972) was the first health economist to come up with a model of demand for health capital. His model is concerned with making a distinction between health capital and other forms of human capital. The model goes beyond the general view of human capital by concept ualising how individuals allocate resources at their disposal to produce health. It utilises the idea of the individual as a producer of health (not simply a consumer) by removing the artificial separation of consumption and production (Grossman, 1972). The model introduced the idea of individuals investing in human capital that is health and education, to improve outcomes in both the market (work) and non-market (household) sec${ }^{2}$ SDG3 requires countries to ensure healthy lives and promote well-being for all at all ages by 2030 (World Health Organisation, 2016). 
tors.

Demand for healthcare is derived from demand for health which means that individuals do not just need healthcare for its own sake, but because of the benefits that are associated with utilisation of healthcare services as individuals seek to keep themselves healthy in order to participate in work and leisure, which gives them utility or satisfaction. Consumers demand health for two basic reasons, as a consumption good or as an investment good. Grossman (1972) argued that the consumption effect, as an element of health demand, is a source of utility and it enters directly into an individual's utility function, implying that individuals feel better when they are healthier. This view posits that increased investment in health increases the number of days available to participate in market (work) production and non-market (household) activities.

Grossman (1972) used the following model to model health as a capital good which is endogenously determined.

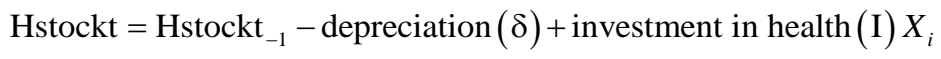

A person is born with initial endowment of health, which they add to by investment. The rate of health production will depend on the efficiency of investment in health. There will be depreciation $(\delta)$ in the value of the stock of health through age, accident, carelessness and sudden disease. Death is assumed to occur when the level of health stock deteriorates below a certain minimum point. The individual is a producer of health who buys market inputs that are medical care, food, and clothing, and combine them with own time to produce services that increase utility in a lifetime. The analysis is based on human capital theory which shows how individuals invest in themselves for example through training or education, to increase their productivity. The optimal amount of investment in human capital is determined by the relative consumption and investment behaviour. Usually consumption occurs in the short-term whilst the behaviour accrues in the future in the form of enhanced job opportunities.

Grossman's model has several predictions based on age, education and wages. In the investment version of the model, there exist a negative relationship between age of an individual and their demand for health as age reduces the incentive to invest in health. Predictions within the consumption model are that, there is a decrease in health stock as age increases since the aged people become more prone to diseases and as such visits the clinics and hospitals more often than the youthful ones. Both the investment and consumption versions in the Grossman model predict that education has a positive relationship with demand for health through increasing the efficiency of non-market production and the marginal productivity of health inputs. Subsidising the price of health inputs (for example, milk and heating) will result in improved health for those receiving such subsidies. For wages in the consumption version, an increase in wages reduces the demand for health because the higher the wage, the higher the marginal cost of holding health stock as consumption good. Conversely, in the investment ver- 
sion, rising wage increases the incentive to work and the incentive to be healthy by increasing the returns to health capital, hence workers who earn higher wages tend to increase their optimal stock of health.

Despite its great intuitive appeal and many insights that it provides in health economics, the Grossman model is criticised for assuming that healthcare is a constant life time investment, ignoring insurance markets that are capable of improving individual's health investments. It also assumes perfect information on the part of consumers about the marginal efficiency of capital of individual healthcare, interest rates and depreciation, which is not the case in the real world. Individuals have different rates at which they depreciate their health stocks due to differences in habits, such as smoking and drug abuse. The model also predicts a positive relationship between health stock and demand for healthcare services ignoring the effects of socio-economic factors (Galama \& Kapteyn, 2011). In summary, demand for healthcare is hypothesized in the theory to depend on age, sex, education, time variables, in addition to price and income.

\subsubsection{Andersen's Health Care Utilisation Model, 1968}

This model by Andersen was developed to help explain differences in access to health services in the USA (Satayavongthip, 2001). According to Andersen, healthcare utilisation is determined by three classes of factors. These three categories are predisposing factors, enabling factors and need based characteristics as depicted in Figure 4.

Enabling characteristics or conditions make health service resources available to individuals. Despite being predisposed to health services, there is need for some means for an individual to utilize healthcare services. These factors encompass individual and household resources, that is, income and health insurance. There are also some community based factors that act as enabling characteristics and these include the availability of healthcare centres such and adequate human resources (staff) at health institutions. Even with enabling factors and being predisposed, individual's decision to seek healthcare services largely depends on need based characteristics. If individuals weigh the severity of illness or their medical condition, they will opt between self or family treatment and healthcare services from professional health centres, the former being given preference when the health problem is considered trivial and the later where the illness is perceived to be severe.

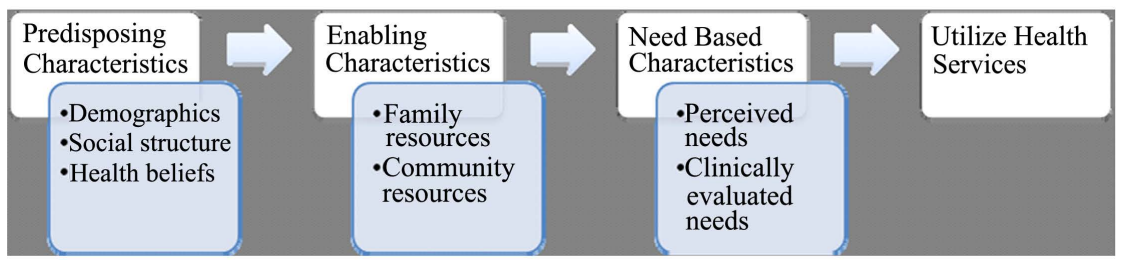

Figure 4. Andersen's health behavioural model of health care service utilisation (Adapted from Anderson (1968)). 
Andersen \& Newman (1973) modified the Andersen utilisation model, taking into account the quality of healthcare systems which include the amount and quality of capital and labour, including the skills and education of healthcare professionals and available equipment. Drawing from the 1970 revised model, it is implicit that the rate of utilisation of healthcare services is largely determined by the population and characteristics of healthcare systems (Andersen \& Newman, 2005; Anderson, 1968). Population characteristics include predisposing, enabling and need-based characteristic while characteristics of healthcare systems include health policy, resources and organisation.

From the Andersen Behavioural model of healthcare utilisation, the dependent variable takes different forms of healthcare service utilisation and consumer satisfaction with healthcare use which include the number of antenatal care visits, place of delivery and assistance during delivery, while possible health outcome measures are maternal and child mortality rates. Stemming from this model, a set of explanatory variables that can possibly be found in the Zimbabwe Demographic Health Survey Data Set include; age, household size and status, residential area, education and health insurance cover. The Andersen model provides a good theoretical framework in analysing determinants of maternal healthcare services in Zimbabwe. Hence, the model provides a good basis for the establishment of a set of explanatory variables in this study. However, this ignores the importance of distance as a factor which affects healthcare service use, especially in the rural areas.

\subsubsection{Young's Choice Making Model, 1981}

Young's Choice Making Model of 1981 was developed based on variations in different ethnic groups that were found in Mexico. It is a health service seeking model that has four determinants which are important to an individual's choice for utilising healthcare services namely; perception of gravity of health problem and culture, knowledge of home treatment, faith or confidence in treatment and treatment availability or accessibility. Individual and societal perceptions pertaining to the seriousness of the illness determines the willingness to utilize healthcare services by individuals. Culture also plays an important role as to whether individuals will utilize healthcare services or not. According to this model, culture is referred to as practises, values, and beliefs within a social group. It includes religious and traditional beliefs. Culture often plays a major role in the utilisation of healthcare services. Some religious and traditional societies do not believe in usage of professional healthcare services. In this study, point of reference is largely made to the apostolic sect, which constitutes a considerable proportion of Zimbabwe's population.

Availability or accessibility of treatment incorporates a consideration of socio-economic status, travel distance to the facility and quality of the healthcare services. Individuals of lower socio-economic status are less likely to utilise professional healthcare services that require a fee upfront, and are also less likely to utilise services that are far from them. If individuals perceive that it is more ad- 
vantageous to seek home treatment than professional health service they opt for such remedies. Whilst Young's individual and societal characteristics and perceptions matter in real world in as far as utilisation of healthcare services is concerned, the model failed to recognise past experience to utilisation of healthcare services as a major determinant of choice making. Mechanic (1986), argued that past experience with a health problem or facility determines the kind of health services that the person will seek. The current study shall incorporate past experience as one of the covariates in explaining maternal healthcare service utilisation by women in Zimbabwe.

\subsubsection{Health Belief Model by Rosenstock et al. (1994)}

This health utilisation framework proposed and used by Rosenstock et al. (1994) analyses a sick person's decision to take preventive or curative action by considering his perception of a set of interacting variables relating to utilisation of healthcare services. These include, the individual's perceived susceptibility to disease, perception of illness severity, rational perception of benefits versus costs and finally the individual's cues to action which involves the media, friends, family members or relatives, or well-known citizens. An individual's choice to utilize health services is therefore contextually dependent. Figure 5 shows the Health Belief Model.

People's beliefs about health problems, perceived benefits of action and self-efficacy have been suggested by Rosenstock as major reasons behind healthcare service utilisation behaviour. The theoretical constructs of the model are criticized as being too broadly defined and also cues to action are difficult to assess and relate to perceived threat of disease, hence limiting the model's research significance. It is, however, more applicable to the Zimbabwean case. Incorporating environmental and economic factors beyond perception variables could help better predict health behaviour.

\subsection{Empirical Literature Review}

\subsubsection{Geographic Factors}

Empirical studies have shown significance of place of residence in explaining the utilisation of maternal healthcare services. In a study of rural women in Kenya,

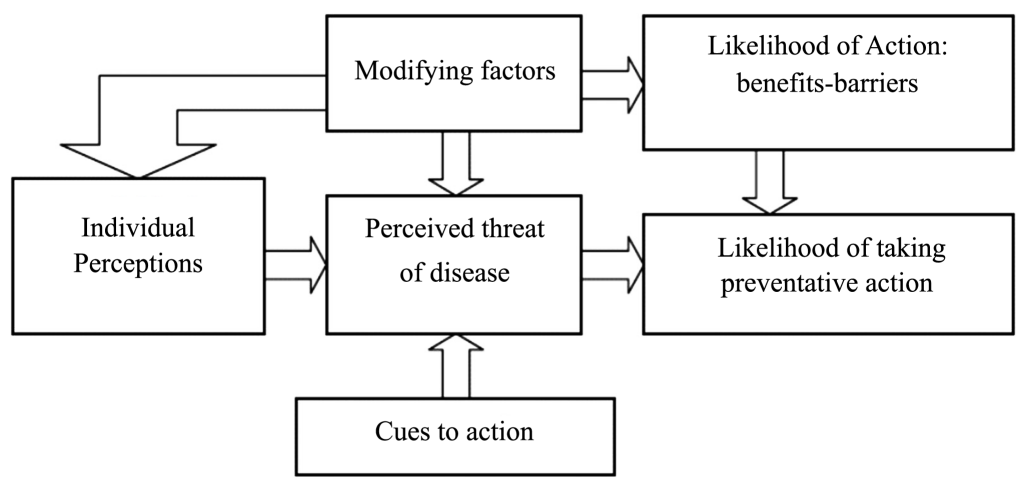

Figure 5. Health belief model, Rosenstock et al. (1994). 
place of residence was found to be the major determinant of the utilisation of both hospital delivery and postnatal care (Chepkorir, 2014). Glei, Goldman, \& Rodríguez (2003) found that distance to the nearest health facility positively influence the utilisation of maternal healthcare services. Other studies that have included this variable include Lidoroh (2013) and Ayele, Belayihun, Teji, \& Ayana (2014) who found similar results that urban dwellers were more likely to use maternal healthcare services as compared to their rural counterparts, mainly because those closer to health centres had reduced perceived risk and they would quickly rush to a health centre in case of emergency. Rajaram, Sunil, \& Zoharelli (2000) found that in most cases, rural dwellers lowly utilise maternal healthcare services as a result of lack of information pertaining to available services.

For Uganda, Rutaremwa (2015) included a regional dummy where results confirmed the existence of disparities in terms of healthcare service utilisation in different regions. Staying in different areas was also found to have an effect on the utilisation of the desirable and moderate packages of maternal health services. The relative risk of utilising desirable MHS package reduced for all other Ugandan regions compared to Kampala, the capital. Eastern Uganda exhibited the lowest log-odds of utilising the desired category of maternal health services. Digambar, Chimankar, \& Harihar (2011) found that shorter distance encourages women to utilise all services of maternal healthcare services that is ANC, delivery in a health institution and PNC use.

\subsubsection{Social-Economic Factors}

Chepkorir (2014) employed a probit regression model to investigate factors that influence utilisation of maternal healthcare services among the rural women in Kenya. The study utilised Kenya Demographic and Household Survey (KDHS) of 2008 with antenatal care, hospital delivery and postnatal care as dependent variables. The study revealed that age of the woman, household size and birth order were determinants of the utilisation of hospital delivery. Oyedele (2017) confirmed theory by supporting the fact that young mothers are more likely to utilize maternal healthcare services as compared to older mothers. Gender of the household head was found to be a determinant of the usage of antenatal care and postnatal care. The study managed to incorporate a wide range of covariates in analysing factors that affect maternal healthcare services (MHCS), providing an insight into factors that affect the utilisation of maternal healthcare services in Zimbabwe. However, the study has its own limitations as it only focused on rural population. To minimise bias arising from focusing on either urban or rural areas only, this study considered both urban and rural population in Zimbabwe.

Rutaremwa (2015) carried out a study on determinants of maternal health services utilisation in Ugandan employing a multinomial logistic regression model using Uganda Demographic Health Survey Data for 2011. A dependent variable called "maternal health services package." was regressed on socio-demographic factors such as age, education level attainment, region of residence, religion, marital status and number of children ever born (predisposing factors). Wealth in- 
dicator was the enabling factor whilst visiting the health facility in the year prior to the survey was used as a proxy for the need factor. Multivariate results show that attaining higher educational levels are associated with increased utilisation of the desirable package of maternal health services, and not the moderate services package. Oyedele (2017) found similar results arguing that an increase in the number of years one spends in school increase the probability of utilising prenatal services. According to the Grossman (1972), human capital investment entails investment in education and health, hence educated people are most likely to utilize maternal healthcare services than those with lower levels of education. Joe \& Mishra (2009) found that higher educational level attracts higher income. This is mainly because educated women have access to maternal health education, thus have knowledge on the benefits of using health facilities.

Some studies such as the one by Chepkorir (2014) ignored the importance of religion in affecting maternal healthcare services. However, Rutaremwa (2015) recognised that religion plays an important role in influencing the choice of utilising maternal healthcare services finding that Muslim women had lower utilisation of MHS package as compared to the Catholics. Rajaram et al. (2000), in a study of women in rural India, also found a substantial variation in the likelihood of utilisation of maternal care services by religion. Only $18 \%$ of the births to Muslim women received excellent maternal care services compared to $38 \%$ of the births to women belonging to religions other than Hindu and Islam. Religion is expected to play an important role in influencing the decision whether or not to utilize maternal healthcare services by women in Zimbabwe.

Individuals from large households are less likely to seek healthcare services from health facilities (Muchabaiwa, Mazambani, Chigusiwa, Bindu, \& Mudavanhu, 2014). This is because the larger the household size is, while household income is constant, the lower per capita income. In households with more members, income may not be adequate to meet the direct and indirect costs of accessing healthcare services. Hence, there are high chances of seeking self-treatment in households with more members as compared to households with fewer members.

Higher birth order of the child was negatively related to safe delivery, with mothers most likely to deliver in the absence of qualified midwifery. Younger mothers and those who received the full ANC were more likely to opt for safe delivery than old mothers and those who did not go for ANC (Digambar et al., 2011). Ayele et al. (2014) found a strong association between birth order and use of healthcare services. This was basically due to perceived risk associated with first pregnancy. Most women are likely to seek maternal healthcare services for first birth than subsequent birth. Underutilization of health services was found to be associated with women with many children due to increased demand especially on their time and resources considering other activities, thus forgoing healthcare (Chamileke, 2017).

Rich women were more likely to utilize healthcare services as compared to the 
poor (Rutaremwa, 2015). A study of Zambian women by Chamileke (2017) also revealed that income determine the use of antenatal care. The study findings were also supported by Govindasamy \& Ramesh (1997) who found out that low income is an obstacle to the use of antenatal care and found that higher social economic status is associated with increased maternal healthcare services utilisation compared to lower social economic groups. The study also gave an insight into what could be the possible dependent variables in this study. It included all the most important measures of maternal healthcare service utilisation that is ANC use, safe delivery and PNC. In a study of Vietnamese women, Tran (2012) found that poorly educated women and those who live in poor communities had less chances of using institutional delivery services.

Digambar et al., (2011) in a study of the factors that influence the utilisation of maternal healthcare services in Uttarakhand, India, found the coefficient of wealth index of the household to be positively related to access to formal delivery facilities. This is so because well to do women have access to information and knowledge and affordability relating to maternal healthcare facilities. Having insurance cover reduces the out-of-pocket expenditure for health services. This, increases accessibility and utilisation of healthcare services. Studies by Kevany et al., (2012) have shown that insurance cover increases the probability of utilising formal healthcare facilities.

\section{Methodology}

\subsection{Theoretical Model and Justification}

Empirical studies, even the ones carried out in the same geographical setting, have not been unanimous of the choice of independent variables in the study of maternal healthcare demand, reflecting different methodologies used. Despite the contradictions in literature regarding the determinants of maternal healthcare services, the study borrows much from the theory of choice making, the Grossman model and the Andersen's Behavioural model.

The study sought to model factors that influence the utilisation of maternal healthcare services by women in Zimbabwe. Women in Zimbabwe are predisposed to healthcare services and it is up to them whether to utilize these services or not. When women are pregnant, they can make a choice as to whether to visit a health facility for antenatal services or not, and a choice of whether to deliver in a health institution or not. After delivery, they may also decide whether to go for postnatal check-ups or not. In each case, the decision to take up the service follows a probability model. It therefore, implies that qualitative response models are most suitable to apply in this study, hence the choice of Logit model using Maximum Likelihood Estimation (MLE) as a technique of estimation.

The assumption of the Logit model is that the error term follows a logistic distribution. The model takes the following functional form:

$$
P_{i} E\left(Y=1 / X_{i}\right)=\beta_{1}+\beta_{2} X_{i} X_{i}
$$

where $P_{i}$ is the probability of seeking maternal healthcare services given a vec- 
tor of explanatory variables, $X_{i}$. The expression can be presented as follows:

$$
P_{i} E\left(Y=1 / X_{i}\right)=\frac{1}{\mathrm{e}^{-\left(\beta_{1}+\beta_{2} X_{i}\right)}} X_{i}
$$

Re-writing the above for ease of exposition gives:

$$
P_{i}=\frac{1}{1+\mathrm{e}^{-z_{i}}}=\frac{\mathrm{e}^{z}}{1+\mathrm{e}^{z}} X_{i}
$$

where $Z_{i}=F\left(\beta_{1}+\beta_{2} X_{i}\right)$.

The above expression represents a cumulative logistic distribution function. $P_{i}$ is non-linear, therefore the OLS procedure cannot be used to estimate the parameters. The above expression can be linearised as follows:

If $P_{i}$, the probability of seeking healthcare services is given as above, then $1-P_{i}$ is the probability of not using healthcare services given by:

$$
1-P_{i}=\frac{1}{1+\mathrm{e}^{z_{i}}} X_{i}
$$

Therefore, the ratio of probability of success to failure (odds ratio), will be written as;

$$
\frac{P_{i}}{1-P_{i}}=\mathrm{e}^{z_{i}} X_{i}
$$

Taking natural logarithms of the above in both sides yields the Logit model given by:

$$
L_{i}=\ln \left(\frac{P_{i}}{1-P_{i}}\right)=Z_{i}=\beta_{1}+\beta_{2} X_{i}
$$

where $L$ is the log of odds ratio which is linear in $X$ and in parameters.

\subsection{Data Sources}

The study used secondary data collected from the 2015 Zimbabwe Demographic and Health Survey (ZDHS). The 2015 ZDHS is the sixth of such surveys conducted in Zimbabwe after the 1988, 1994, 1999, 2005-2006 and 2010-2011 surveys. The 2015 Zimbabwe Demographic and Health Survey (2015 ZDHS) presents the major findings of a nationally representative survey with a sample of more than 11,000 households. The 2015 ZDHS was conducted by the Zimbabwe National Statistics Agency (ZIMSTAT) in collaboration with the Ministry of Health and Child Care (MoHCC) and the United Nations Population Fund (UNFPA), from July through to December 2015. To study the factors affecting utilisation of maternal healthcare services, the study considered the most recent births to women ${ }^{3}$, which took place during the five years prior to the survey. The 2015 ZDHS gathered valuable information on national indicators including maternal and child health (ZimStat, 2015b).

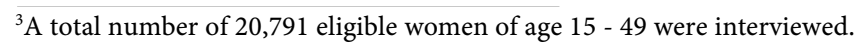




\subsection{Logit Model Specification}

Therefore, guided by theory (Andersen \& Newman, 2005), and borrowing from a study by Chamileke (2017) and augmented to include other socio-demographic variables, the Logit model estimated in this study was specified as:

$$
\begin{aligned}
P\left(\text { dmh }_{=1 / X)=}\right. & \beta_{0}+\beta_{1} \text { mtnage }_{i}+\beta_{2} \text { hinco }_{i}+\beta_{3} \text { plres }_{i}+\beta_{4} \text { insur }_{i} \\
& +\beta_{5} \text { mtedu }_{i}+\beta_{6} \text { chlnm }_{i}+\beta_{7} \text { rresid }_{i}+\beta_{8} \text { hsize }_{i} \\
& +\beta_{9} \text { empst }_{i}+\beta_{10} \text { bthord }_{i}+\beta_{11} \text { rel }_{i}+u_{i} X_{i}
\end{aligned}
$$

where $P(d m h=1 / X)$ is the probability that a woman will seek maternal healthcare services for Antenatal care (ANC), delivery care (DC), and utilisation of postnatal services (PC) given the vector of observable socio-demographic variables. The variable ANC is a dummy and none utilisation of antenatal visits (less than four) was coded zero while utilisation of antenatal visits (at least four) was coded one. Tran (2012) argued that individuals with more number of antenatal visits are most likely to use a health facility during delivery and also have postnatal check-ups than their counterparts. Pregnant women may choose to deliver either at home (0) or in a health institution under the guidance of a qualified officer (1). Choice of postnatal care utilisation is a dichotomous response variable with a zero if the woman chooses not to utilize postnatal care services or one if she decides to utilize postnatal care services. The inclusion of these three variables as dependent variables follows studies by Chamileke (2017) and Digambar et al., (2011). However, Muchabaiwa et al., (2014) also included tetanus injection as the fourth measure of maternal healthcare service utilisation. This study only confined its model to the first three measures of maternal healthcare services since tetanus injection is mainly considered as part of basic ANC utilisation in literature.

Drawing from the theoretical models by Andersen \& Newman (2005), Young, (1981) and Grossman (1972) and reviewed empirical literature, the explanatory variables include socio-economic and demographic factors summarised in Table 2.

\section{Estimation and Presentation of Results}

Descriptive statistics are presented first then followed by the presentation of the econometric results. The model was estimated for each of the three proxies for the dependant variable being place of delivery (DC), Antenatal care (ANC) visits and utilisation of postnatal services (PNC), results of which are given in Tables 3-5.

\subsection{Descriptive Statistics}

Out of 20,791 women, the average age of reproductive women is approximately 35 years. Households have an average of 3 children with average household size of 15 people. The minimum number of years as indicated earlier in ZDHS 2015 is 15 years and the maximum is 49 years. From the statistics, the highest number of living children is 12 , which signal a very high figure. However, on average, the 
Table 2. Summary of explanatory variables (author compilation).

\begin{tabular}{|c|c|c|}
\hline $\begin{array}{l}\text { Variable } \\
\text { Name }\end{array}$ & Variable Description \& Justification & Variable Measurement \\
\hline mtnage & $\begin{array}{l}\text { Age of the mother under study. Young mothers } \\
\text { more likely to utilize maternal healthcare } \\
\text { services compared to old mothers } \\
\text { (Digambar, } 2017 \text { and Oyedele, 2017) }\end{array}$ & No. of years (15 to 49 ) \\
\hline hinco & $\begin{array}{l}\text { The household income with the wealthy } \\
\text { households more likely to utilise maternal } \\
\text { healthcare services compared to poor households. }\end{array}$ & Wealth index ( 1 to 5$)^{4}$ \\
\hline plres & $\begin{array}{l}\text { The place where the woman lives either rural or } \\
\text { urban residence with urban dwellers having } \\
\text { more access than rural (Lidoroh (2013), } \\
\text { Ayele (2014) and Oyedele (2017). }\end{array}$ & $\begin{array}{l}\text { Dummy being } 1 \text { for urban } \\
\text { and } 0 \text { for rural. }\end{array}$ \\
\hline insur & $\begin{array}{l}\text { Health insurance cover which increases the } \\
\text { probability of utilising formal healthcare facilities } \\
\text { (Larsen (2004) and Kevany et al. (2012). }\end{array}$ & $\begin{array}{l}\text { Dummy with } 1 \text { if a woman } \\
\text { has a health insurance } \\
\text { policy and } 0 \text { otherwise. }\end{array}$ \\
\hline mtedu & $\begin{array}{l}\text { The level of education of the woman where the } \\
\text { more educated the woman is, the higher the } \\
\text { probability of utilising maternal healthcare } \\
\text { services mediated through higher income } \\
\text { (Joe \& Mishra, 2009). }\end{array}$ & Categorical variable ${ }^{5}$ \\
\hline chlnm & $\begin{array}{l}\text { The number of living children that a woman } \\
\text { has at last pregnancy as a proxy for woman } \\
\text { prior experience to utilisation of healthcare } \\
\text { facilities. Utilisation of maternal healthcare } \\
\text { services decreases with an increase in the } \\
\text { number of children. }\end{array}$ & No. of children \\
\hline rresid & $\begin{array}{l}\text { The region of residence (province) being an } \\
\text { indicator of extent of inequality in healthcare } \\
\text { infrastructure availability (Rutaremwa, 2015). }\end{array}$ & $\begin{array}{l}\text { Regional dummies } \\
\text { ( } 1-6 \text { for the } 6 \text { Provinces })\end{array}$ \\
\hline rel & $\begin{array}{l}\text { The religion of the woman. Being apostolic } \\
\text { reduces the probability of utilising maternal } \\
\text { healthcare services (Chepkorir et al. 2014). }\end{array}$ & $\begin{array}{l}\text { Dummy being } 1 \text { for } \\
\text { apostolic sect and } \\
0 \text { otherwise. }\end{array}$ \\
\hline hsize & $\begin{array}{l}\text { Household size being the number of members } \\
\text { in the household. Individuals from large } \\
\text { households less likely to seek healthcare } \\
\text { services from healthcare facilities mediated } \\
\text { through income (Muchabaiwa et al., 2013). }\end{array}$ & $\begin{array}{l}\text { Number of members } \\
\text { in the household. }\end{array}$ \\
\hline empst & $\begin{array}{l}\text { Employment status of the woman with } \\
\text { employment increasing chances of using } \\
\text { healthcare facilities to the extent the woman } \\
\text { control her income (Addai, 2000). }\end{array}$ & $\begin{array}{l}\text { Dummy variable } 1 \text { for } \\
\text { employed women and } \\
0 \text { otherwise. }\end{array}$ \\
\hline bthord & $\begin{array}{l}\text { Birth order capturing whether the child was a first } \\
\text { born, second born or any position at the time of } \\
\text { survey being another proxy for woman prior } \\
\text { experience to utilisation of healthcare facilities. }\end{array}$ & $\begin{array}{l}1 \text { for } 1^{\text {st }} \text { born, } 2 \text { for } \\
2^{\text {nd }} \text { born up } \mathrm{n} \text { for } \mathrm{n}^{\text {th }} \text { born. }\end{array}$ \\
\hline$\mu$ & a stochastic error term & \\
\hline$\beta_{i} s$ & constants & \\
\hline
\end{tabular}

${ }^{4}$ The wealth index was constructed using 2015 ZDHS household possession data with a code two for poorest and three for poorer households, one for middle income households and four for richer and five for richest households.

${ }^{5}$ Women with no education were coded zero; those with primary education were coded one, two was coded to those with at least secondary education and lastly three. 
Table 3. Marginal effects results for place of delivery.

\begin{tabular}{|c|c|c|c|c|c|c|}
\hline \multirow{2}{*}{ Variable } & \multirow{2}{*}{ Margin } & \multirow{2}{*}{ Std Err } & \multirow{2}{*}{$\mathrm{Z}$} & \multirow{2}{*}{$P>z$} & \multicolumn{2}{|c|}{ 95\% Conf Inter } \\
\hline & & & & & Lower & Upper \\
\hline Place of res & 0.1794304 & 0.0212928 & 8.43 & 0.000 & 0.1376973 & 0.2211635 \\
\hline \multicolumn{7}{|l|}{ Reg of resid } \\
\hline Harare & 0.1039378 & 0.0352799 & 2.95 & 0.003 & 0.03479 & 0.1730849 \\
\hline Mashonaland & -0.0546657 & 0.0310119 & -1.76 & 0.078 & -0.115448 & 0.0061166 \\
\hline Matebeleland & 0.1027118 & 0.032429 & 3.17 & 0.002 & 0.0391696 & 0.166254 \\
\hline \multicolumn{7}{|l|}{ Level of edu } \\
\hline 2 & -0.2309221 & 0.068382 & -3.38 & 0.001 & -0.364948 & 0.968959 \\
\hline 3 & -0.1850166 & 0.405953 & -4.56 & 0.000 & -0.264582 & -0.1054512 \\
\hline 4 & -0.1261373 & 0.385552 & -3.27 & 0.001 & -0.201704 & -0.0505705 \\
\hline Religion & -0.0564831 & 0.114888 & -4.92 & 0.000 & -0.079008 & -0.0339655 \\
\hline \multicolumn{7}{|l|}{ Hhold inc } \\
\hline Poorer & -0.0788228 & 0.0186809 & -4.22 & 0.000 & -01154416 & -0.0422138 \\
\hline Poorest & -0.1270805 & 0.0191401 & -6.44 & 0.000 & -0.164594 & -0.0895666 \\
\hline Richer & 0.0536795 & 0.0227269 & 2.36 & 0.018 & 0.0091356 & 0.0982233 \\
\hline Richest & 0.1104481 & 0.0297922 & 3.71 & 0.000 & 0.0520564 & 0.1688399 \\
\hline Insur cover & 0.1274126 & 0.0334876 & 3.80 & 0.000 & 0.0617781 & 0.1930471 \\
\hline Birth order & -0.035457 & 099.00783 & -4.52 & 0.000 & -0.050823 & -0.0200911 \\
\hline Age & 0.0045569 & 0.0012745 & 3.58 & 0.000 & 0.0020589 & 0.0070548 \\
\hline
\end{tabular}

Table 4. Marginal effects results for the antenatal care.

\begin{tabular}{ccccccc}
\hline Variable & Margin & Std Err & $\mathrm{Z}$ & $\mathrm{P}>\mathrm{Z}$ & \multicolumn{2}{c}{$95 \%$ Conf Int } \\
\cline { 6 - 7 } & & & & & Lower & Upper \\
\hline Place of resid & -0.027711 & 0.014224 & -1.95 & 0.051 & -0.05589 & 0.001663 \\
Maternal educ & & & & & & \\
primary & 0.036063 & 0.021793 & 1.65 & 0.098 & -0.0065 & 0.078776 \\
secondary & 0.045395 & 0.018968 & 2.39 & 0.017 & 0.0082 & 0.082571 \\
Insur cover & -0.022927 & 0.009054 & 2.53 & 0.011 & -0.0407 & 0.005182 \\
Emp stat & 0.017532 & 0.006484 & 2.70 & 0.007 & 0.0048 & 0.302400 \\
Age & -0.001186 & 0.000626 & -1.90 & 0.058 & -0.0241 & 0.000040 \\
\hline
\end{tabular}

Table 5. Marginal effects results for postnatal care.

\begin{tabular}{|c|c|c|c|c|c|c|}
\hline \multirow{2}{*}{ variable } & \multirow{2}{*}{ Margin } & \multirow{2}{*}{ St Err } & \multirow{2}{*}{$\mathrm{Z}$} & \multirow{2}{*}{$P>z$} & \multicolumn{2}{|c|}{$95 \%$ Conf Interval } \\
\hline & & & & & Lower & Upper \\
\hline \multicolumn{7}{|c|}{ Region of res } \\
\hline Harare & 0.079911 & 0.029468 & 2.71 & 0.007 & 0.0221543 & -0.137667 \\
\hline
\end{tabular}




\begin{tabular}{|c|c|c|c|c|c|c|}
\hline \multicolumn{7}{|l|}{ Continued } \\
\hline Mashonaland & 0.106079 & 0.027155 & 3.91 & 0.000 & 0.0528554 & -0.159302 \\
\hline Matebeleland & 0.071603 & 0.028540 & 2.51 & 0.012 & 0.0156645 & -0.127541 \\
\hline Midlands & 0.118519 & 0.286524 & 4.14 & 0.000 & 0.0623613 & -0.174677 \\
\hline Level of educ & -0.05467 & 0.286524 & -1.95 & 0.051 & -0.109553 & -0.000213 \\
\hline \multicolumn{7}{|l|}{ Hhold inc } \\
\hline Poorer & -0.039893 & 0.018005 & -2.22 & 0.027 & -0.075182 & -0.004603 \\
\hline Poorest & -0.037794 & 0.017515 & -2.16 & 0.031 & -0.0721227 & -0.003465 \\
\hline Chlnm & 0.060928 & 0.009650 & 6.31 & 0.000 & 0.042015 & -0.079842 \\
\hline Age & 0.004812 & 0.001271 & 3.79 & 0.000 & 0.0023212 & -0.007304 \\
\hline
\end{tabular}

number of living children is relatively low, that is 3. Most households in Zimbabwe are characterised by large number of members as show by a maximum of 29 members per household and a minimum of 15 members per household.

The majority (32.8\%) of the 20,791 sampled women were from Mashonaland province, which is mostly rural than other provinces in Zimbabwe. About $81.58 \%$ were married and $18.42 \%$ were single. More than half of the women interviewed were not employed and almost $90 \%$ of the women were not covered by insurance. Due to high levels of unemployment the level of the poor and poorest quintile is quite high. The apostolic sect constituted about $46 \%$ of the sample.

\subsection{Pre-Estimation and Diagnostic Tests}

Multicollinearity test was done to test for correlation between explanatory variables. To do this, pair wise correlation matrix was used. The rule of thumb is that if pair-wise correlation coefficient between two explanatory variables is above 0.8 in absolute value, multicollinearity exists (Gujarati, 2003). In such a case, one of the highly correlated variables should be dropped. The problem of multicollinearity may result in large variances that are meaningless and give rise to biased results. Test results shows that there was no problem of multicollinearity on all variables of the four models since the absolute values of the Pearson correlation matrix pair wise coefficient were all less than 0.8

Hosmer-Leme show goodness of fit test was used to test for the overall goodness of fit of the model reflected by non-significant p-values for the three categories of maternal healthcare.

\subsection{Presentation of Econometric Results}

Marginal ${ }^{6}$ effects were computed to provide a measure of effects of unit changes of the predictor variables on the probabilities of choosing a particular outcome of the dependant variable. Marginal effects are defined as the slope of the predic-

${ }^{6}$ Marginal effects are computed only for those variables whose coefficients were significant at the $1 \%$, $5 \%$ or $10 \%$ level of significance. 
tion function. They provide information about a change in predicted probabilities that is due to a unit change in the explanatory variable. In factor (dummy) variables, marginal effects gives information on the change in predicted probabilities as the variable changes from the reference category, hence it is the difference between predicted probabilities between a category and the reference category. Marginal effects are more useful than slope coefficients of discrete response models since marginal effects estimate the change in probability whereas slope coefficients simply give the relative odds ratio in favour of a particular outcome (Wooldridge, 2004).

\section{Discussion of Results}

\subsection{Geographic Factors}

Consistent with general findings in literature (Muchabaiwa et al., 2014; Tran, 2012), the study results revealed that residing in urban areas increases the chances of utilising maternal healthcare facilities by $17.94 \%$. This is largely because women in urban areas are better placed in terms of information, knowledge and access to maternal healthcare services as compared to their rural counterparts, hence more likely to deliver in health facilities. In addition, healthcare services are more distributed in urban areas than in rural areas thereby increasing accessibility of these services in urban areas.

Marginal effects results show that residing in Harare reduces the probability of utilising antenatal services by $2.77 \%$ compared to Bulawayo. These results are influenced by the fact that residences in the capital city of Harare have a wider choice of health service centres which make them become less threatened by possible obstetric risks. However, residing in Harare and Matabeleland increases the probability of delivering in a healthy institution by $10.39 \%$ and $10.27 \%$ respectively as compared to residing in Bulawayo, whilst residing in Mashonaland province reduces the probability of delivering in a healthy institution by $5.47 \%$. The reason for a higher probability of delivering at a health institution in Harare as compared to Bulawayo could be a result of a large number of these health institutions found in Harare than in Bulawayo. As for Matabeleland, which then excludes Bulawayo town, could be a result of activities of Non-Governmental Organisations (NGOs) and some missionary hospitals providing free maternal healthcare services.

When it comes to utilising postnatal services, the positive coefficients imply that residing either in Harare, Mashonaland, Matabeleland or Midlands increases the probability of utilising postnatal care by $7.99 \%, 10.61 \%, 7.16 \%$ and $11.85 \%$ respectively. Explanations that could be attached to such results are that Harare has a diversity of health centres for postnatal check-ups, whilst Mashonaland, Matabeleland and Midlands all have a wide range of missionary hospitals and various NGOs that allow women free maternal healthcare services.

\subsection{Economic Factors}

Study results show that an employed woman has a higher chance of utilising an- 
tenatal services than a woman who is currently unemployed. Being employed increases the probability of utilising antenatal care services by $1.75 \%$. This is in line with the findings of Nigatu, Gebremariam, Abera, Setegn, \& Deribe (2014), who found out that both employment status and job type are key determinants of willingness to partake in health and healthcare programmes in Ethiopia.

Results show that being poorer and poorest lowers the probability of delivering in a health institution by $7.88 \%$ and $12.70 \%$ respectively. Categories being richer and richest increase the probability of delivering in a health institution by $53.68 \%$ and $11.04 \%$ respectively. Equally so, being poorer and poorest reduces the probability that a woman goes to a health centre for postnatal check-up and compared to middle income earners with predicted probabilities being 3.99\% and $3.78 \%$ respectively. In general, these marginal effects results show that the probability of maternal healthcare services in Zimbabwe increases with increase in wealth level. A number of studies also found similar results (Chamileke, 2017; Grossman, 1972; Rutaremwa, 2015).

These results show that having insurance cover increases the probability of using health facility for delivery by $12.74 \%$ in Zimbabwe. Having insurance cover reduces the out of pocket costs that pregnant women will have to pay, hence increases accessibility and utilisation of maternal healthcare services (Rajaram et al., 2000). However, when it came to use of antenatal care, the marginal effects results show that having insurance cover reduces the probability of visiting a health centre for antenatal check up by $2.3 \%$. This is contrary to most study findings that have shown that having insurance cover increases the utilisation of antenatal care services by women since there will be reduced out of pockets payments. Results from this study could be explained by the fact that those with health insurance cover are most likely to be risk takers and therefore not afraid of emergency medical requirements during pregnancy. As a result, they are less likely to use antenatal care services.

\subsection{Social Factors}

Coming to characteristics of the mother, study results suggest negative relationship between age of a woman and the probability of utilising antenatal care services. From theory, ageing leads to rising depreciation in health stock which implies increasing marginal cost of health investment. The demand for health capital is, thus, expected to fall with age (Grossman, 1972). Age can be negatively related to healthcare utilisation since it captures past maternal experience especially where there were no complications in previous pregnancies and child health (Chepkorir, 2014).

However when it came to place of delivery, a one year increase in the age of a respondent will lead to a $0.45 \%$ increase in the probability of delivering in a health institution contrary to a-priori expectations. However, such a result may be a reflection of past complications in women which prompted them to use healthcare facility for delivery. In terms of using postnatal care facilities, results 
show that a one year increase in maternal age of a respondent will lead to a $0.48 \%$ increase in the utilisation of postnatal care services by a woman. Thus, the older a woman gets, the more they want to use postnatal care services.

An increase in education level is associated with an increase in probability of utilising antenatal care services with marginal effects for secondary education and tertiary education at $3.61 \%$ and $4.54 \%$ respectively. Muchabaiwa et al., (2014) also found similar results. Similarly, the number of years the respondent spends in education is positively related to the choice of place of delivery. This corroborates with the postulations of Grossman theory and findings of many others studies in literature (Elo, 1992) that an increase in the number of years spent at school increases the probability of utilisation of health institutions.

The effect of education level on use of postnatal care services was equally positive, suggesting that regardless of proxy used, a higher education qualification result in increased probability of utilising maternal healthcare services. This is consnsietenlt with Grossman's model which predicted that education would influence demand for healthcare positively as educated mothers improve understanding and appreciation of benefits of seeking healthcare services during and after pregnancy.

Results from the study show that being a member of the apostolic sect reduce the probability of delivering in a health institution by $5.64 \%$. This is because the teaching of the sect discourages use of formal healthcare facilities in favour of spiritual solutions usually provided in the sect itself. This result is in tandem with findings by UNICEF (2011) also found that members of the apostolic sect are not allowed to immunize their babies at the conventional clinics or hospitals.

The coefficient of the variable of birth order is negative suggesting that as the number of children increases, the probability of delivering in a health institution by a woman decreases by $3.55 \%$. The result could be attributed to the fact that as the number of children increases, and especially in cases where there are no previous records of medical complications, then the woman will have gained experience and will be less afraid of any possible obstetric complication hence delivering at home. The results in Table 5 show a negative relationship between birth order of a child and the utilisation of postnatal care services, suggesting that a higher order child (in terms of birth) reduces the probability of utilising postnatal healthcare services by $7.42 \%$, consistent with findings in literature.

The coefficient of the variable on number of living children is positive and statistically significant at $1 \%$ level of significance. An increase in the number of children increases the probability of utilising postnatal care services by a woman by $6.09 \%$. This result is quite unfamiliar as most studies found out that as the number of children increases, the probability of a woman utilising maternal healthcare services decreases. This result could have been influenced by the fact that some women may have experienced some past obstetric complications and as a result would need to have postnatal check-ups to avert such possible mishaps. 


\section{Conclusion and Policy Recommendations}

\subsection{Summary of Findings}

The study investigated factors that determine the uptake of maternal healthcare services by women in Zimbabwe. This has partly been a result of low utilisation of maternal healthcare services in the country despite efforts by the government of Zimbabwe to improve the availability of these services in the country (MoHCC, 2016). Specifically, the study explored factors that influenced the three components of maternal healthcare namely; antenatal care utilisation, delivering in a health institution and postnatal care utilisation. A set of socio-economic and demographic factors were used as covariates. The study used 2015 Zimbabwe Demographic Health Survey cross sectional data.

Overall, the coefficient of region of residence (residing in Harare) was found to be statistically significant in explaining ANC, deliver utilisation and postnatal check-ups. Residing in Harare reduced the probability of utilising antenatal care services as compared to residing in Bulawayo. On the contrary, residing either in Harare or Matabeleland was found to increase the probability of delivering in a health institution and using a postnatal check-up as compared to Bulawayo. Also, residing in urban areas increases the probability of delivering in a health institution than residing in the rural areas. However, residing in Mashonaland reduced the probability of delivering in a health institution as compared to Bulawayo.

Level of education was also found to be a determinant of all the three indicators of maternal healthcare services. An unusual result was that having a higher educational qualification reduced the probability of delivering in a health institution and reduced the uptake of postnatal care services. An increase in the number of years of a woman also reduced the probability of utilising ANC services whilst place of residence, woman education level and insurance cover have a positive influence on the utilisation of ANC. Age of the woman and as expected, birth order reduced the likelihood of women delivering in a health institution. Age of the woman and number of living children encouraged the use of postnatal care. Being a member of the apostolic sect was also found to have a reducing effect on the probability of maternal healthcare facilities.

Insurance cover, employment status and income status had strong marginal effects with income categories the poorer and the poorest reducing the probability of using maternal healthcare facilities whilst the richer and the richest increased the probability of delivering in a health institution. Having insurance cover increased the probability of using healthcare facilities.

On limitations, the 2015 ZDHS did not capture information on the quality and attributes of services that were provided by healthcare workers. It is important to note that quality of services provided may influence repeat behaviour, that is women will keep on visiting the health facility if there are high quality services offered. When this happens, the problem of low utilisation of maternal healthcare services will be averted in all provinces in Zimbabwe. The 2015 ZDHS 
also did not include information on distance to the nearest health facility. Factoring in quality of service provision can potentially alter the conclusions of this study and therefore resources permitting it is an area of further study that needs to be pursued. However, regardless of these few limitations, study findings from this research are important for policy formulation in the wake of government's effort to reduce maternal and child mortality through greater maternal healthcare service utilisation.

\subsection{Policy Implications and Recommendations}

There are several policy insights that can be derived from the empirical findings of this study. Given that higher education was found to increase the probability of utilising antenatal care services, vocational training centres may be established in both rural and urban areas to help avert the problem of non-utilisation of healthcare services. Vocational training enhances knowledge and also lightens prospects of being employed in women and improves women's access to and use of healthcare services. Education should go beyond formal education but awareness programs that cover even the apostolic sect members to be aware of the benefits of delivering in a health institution and also the possible dangers associated with delivering outside a health institution. Electronic and mass media can be leveraged for greater reach in this respect. The government with the help of development partners should increase awareness on the importance of family planning and ensure increased access to contraceptives so that the number of children is not a deterrent to uptake of maternal healthcare facilities.

Since most economic variables were found to influence uptake of maternal healthcare facilities, it is important that government addresses the issue of unemployment that has reached unsustainable levels. Higher incomes means more affordability and also ability to subscribe to health insurance programs. The government could also subsidise maternal healthcare facilities in both rural and urban areas in the absence of national healthcare insurance scheme which is long overdue. For regions like Mashonaland and Matebeleland where low uptake is likely reflecting poor infrastructure, there is need to leverage the devolution agenda to attend to issues of equity in development of maternal healthcare infrastructure down to the Ward level.

\section{Conflicts of Interest}

The authors declare no conflicts of interest regarding the publication of this paper.

\section{References}

AHFoZ (2016). Zimbabwe Health Financing: Our Approach to HFP Development. Harare.

Andersen, R. M., \& Newman, J. (1973). Societal and Individual Determinants of Medical Care Utilization in the United States. Milbank Memorial Fund Quarterly-Health and Society, 51, 95-124. https://doi.org/10.2307/3349613 
Andersen, R., \& Newman, J. F. (2005). Societal and Individual Determinants of Medical Care Utilisation in the United States. Milbank Quarterly, 83, 184-196. https://doi.org/10.1111/j.1468-0009.2005.00428.x

Anderson, R. W. (1968). A Behavioural Model of Families Use of Health Services. Health Economics Review.

Ayele, D. Z., Belayihun, B., Teji, K., \& Ayana, D. A. (2014). Factors Affecting Utilisation of Maternal Health Care Services in Kombolcha District, Eastern Hararghe Zone, Oromia Regional State, Eastern Ethiopia. https://doi.org/10.1155/2014/917058

Chamileke, N. (2017). Socio Demographic Determinants of Maternal Health Service Utilization among Women 15 to 49 Years in Zambezi District in Northwestern Zambia. Medical Journal of Zambia, 44, 149-156.

Chepkorir, J. (2014). Determinants of Maternal Healthcare Utilisation in Rural Kenya. Nairobi: University of Nairobi.

Digambar, A., Chimankar, B., \& Harihar, S. (2011). Factors Influencing the Utilisation of Maternal Health Care Services in Uttarakhand. Studies on Ethno-Medicine, 5, 209-216. https://doi.org/10.1080/09735070.2011.11886411

Elo, I. T. (1992). Utilization of Maternal Health-Care Services in Peru: The Role of Women's Education. Health Transition Review, 2, 1-20.

Fauveau, V., Koenig, M. A., Chakraborty, J., \& Chowdhury, A. I. (1988). Causes of Maternal Mortality in Rural Bangladesh, 1976-85. Bulletin of the World Health Organization, 66, 643-651.

Galama, T. J., \& Kapteyn, A. (2011). Grossman's Missing Health Threshold. Journal of Health Economics, 30, 1044-1056. https://doi.org/10.1016/j.jhealeco.2011.06.004

Glei, D. A., Goldman, N., \& Rodríguez, G. (2003). Utilization of Care during Pregnancy in Rural Guatemala: Does Obstetrical Need Matter? Social Science and Medicine, 57, 2447-2463. https://doi.org/10.1016/S0277-9536(03)00140-0

Govindasamy, P., \& Ramesh, B. M. (1997). Maternal Education and the Utilization of Maternal and Child Health Services in India. National Family Health Survey Subject Reports, Mumbai.

Grossman, M. (1972). On the Concept of Health Capital and the Demand for Health. Journal of Political Economy, 80, 223-255. https://doi.org/10.1086/259880

Gujarati, D. N. (2003). Basic Econometrics (4th ed.). New York: McGraw-Hill Publishing Company.

Joe, W., \& Mishra, U. (2009). Household Out-of-Pocket Healthcare Expenditure in India Levels, Patterns and Policy Concerns. Journal of Public Health in Asia, 4, 79-98.

Kadenge, P. G., Ndoro, H., \& Zwizwai, B. (1992). Zimbabwe's Structural Adjustment Programme: The First Year Experience. Harare: Sapes Books.

Kanyenze, G., Kando, P., Chitambara, P., \& Martens, J. (2012). Beyond the Enclave: Towards a Pro-Poor and Inclusive Development Strategy for Zimbabwe. Harare: Weaver Press. https://doi.org/10.2307/j.ctvk3gmdw

Kawewe, S., \& Dibie, R. (2000). The Impact of Economic Structural Adjustment Programs [ESAPs] on Women and Children: Implications for Social Welfare in Zimbabwe. Journal of Sociology and Social Welfare, 27, 79-107.

Kevany, S., Murima, O., Singh, B., Hlubinka, D., Kulich, M., Morin, S. F., \& Sweat, M. (2012). Socio-Economic Status and Health Care Utilization in Rural Zimbabwe: Findings from Project Accept (HPTN 043). Journal of Public Health in Africa, 3, 46-51. https://doi.org/10.4081/jphia.2012.e13

Lidoroh, A. S. (2013). Determinants of Postnatal Care Use in Kenya. African Population 
Studies Journal, 28, 59-62. https://doi.org/10.11564/28-3-638

Mechanic, D. (1986). Illness Behavior: A Multidisciplinary Model. In S. McHugh, \& T. M. Vallis (Eds.), Illness Bevaviour (pp. 101-109). Boston, MA: Springer US.

MoHCC (2016). The National Health Strategy for Zimbabwe 2016-2020. Harare: Zimbabwe Ministry of Health and Child Care.

MoHCC (2017). Zimbabwe's E-Health Strategy. Harare: Ministry of Health and Child Welfare.

Muchabaiwa, L., Mazambani, D., Chigusiwa, L., Bindu, S., \& Mudavanhu, V. (2014). Determinants of Maternal Healthcare Utilization in Zimbabwe. International Journal of Economic Sciences and Applied Research, 5, 145-162.

Nigatu, D., Gebremariam, A., Abera, M., Setegn, T., \& Deribe, K. (2014). Factors Associated with Women's Autonomy Regarding Maternal and Child Health Care Utilization in Bale Zone: A Community Based Cross-Sectional Study Factors Associated with Women's Autonomy Regarding Maternal and Child Health Care Utilization in Bale. BMC Women's Health, 14, 1-10. https://doi.org/10.1186/1472-6874-14-79

Oyedele, O. (2017). Determinants of Maternal Healthcare Utilization in Nigeria. African Research Reviews, 11, 283-294. https://doi.org/10.4314/afrrev.v11i2.21

Rajaram, S., Sunil, T. S., \& Zoharelli, L. K. (2000). Do Individual and Programme Factors Matter in the Utilisation of Maternal Care Services in Rural India? A Theoretical Approach. Journal of Human Resources, 28, 838-862.

Rosenstock, I., Stretcher, V., \& Becker, M. H. (1994). The Health Belief Model and HIV Risk Behaviour Change. New York: Plenum Press. https://doi.org/10.1007/978-1-4899-1193-3 2

Rutaremwa, N. M. (2015). Determinants of Maternal Healthcare Utilisation in Uganda. National Centre for Epidemiology and Population Health (NCEPH), 3, 34-56. https://doi.org/10.1186/s12913-015-0943-8

Satayavongthip, W. (2001). Determinants of and Inequality in Household Expenditure on Health Care in Thailand.

Tran, K. T. (2012). Antenatal and Delivery Care Utilisation in Urban and Rural Contexts in Vietnam: A Study in Two Health and Demographic Surveillance Sites.

UNICEF (2011). Apostolic Religion, Health and Utilization of Maternal and Child Health Services in Zimbabwe. Harare.

Wooldridge, J. M. (2004). Econometric Analysis of Cross Section and Panel Data. Cambridge, MA: The MIT Press.

World Health Organisation (2013). Communicating the Economics of Social Determinants of Health and Health Inequalities - A Resource Book. Geneva: World Health Organisation. http://www.who.int/iris/handle/10665/85260

World Health Organisation (2016). Public Financing for Health in Africa: From Abuja to the SDGs. Health Financing toward UHC Public.

http://www.who.int/healthsystems/topics/financing/healthreport/en

Young, J. C. (1981). Medical Choice in a Mexican Village. New Brunswick, NJ: Rutgers University Press.

ZimStat (2015a). Maternal Health ZDHS 2015 Key Findings.

Zimstat (2015b). Zimbabwe Demographic and Health Survey (ZHDS). Harare. 